\title{
ETHICAL SUPERVISION AND MENTORING OF STUDENTS DURING THE WORK-INTEGRATED LEARNING PROGRAMME
}

\author{
Cabangile N. Ngwane ${ }^{1}$
}

\begin{abstract}
The study investigates ethical supervision and mentoring during work-integrated learning (WIL) placement as WIL has emerged as a new venture in higher education. Work-integrated learning has emerged as a higher education endeavour that has created a new role for senior leadership and management. The study aims to investigate the ethical supervision and mentoring of students during the work-integrated learning programme in order to contribute to the effectiveness of the programme and improve student employability. More work has been done on work-integrated learning however, little has been done on the ethical supervision and mentoring of students during WIL. The study contributes to the debate of WIL implementation. The study revealed that there is a lack of adequate training for supervisors, which sometimes results in students running errands. The positivist research paradigm underpinning the study led to the use of a survey research design and questionnaires. During the research process, research ethical rules had been adhered to in order to ensure reliability of findings. A socio-cultural theory has been employed.
\end{abstract}

UDC Classification: 314.37; DOI: http://dx.doi.org/10.12955/cbup.v5.1018

Keywords: Supervision, Mentoring, Employability and Work Integrated Learning.

\section{Introduction}

Work-integrated learning has emerged as a higher education endeavour that has created a new role for senior leadership and management. WIL encompasses other aspects including supervision and mentoring. Supervision addresses the aspects of support and integration. The supervisory process places emphasis on the relationship between students and supervisors. On the other hand, the idea of mentoring is about the development of a relationship, focussing on longer term and well-defined academic and social achievement. Both mentors and students should gain intellectual, emotional and personal achievement from the experience. The study aims to investigate the ethical supervision and mentoring of students during in the work-integrated learning programme in order to contribute to the effectiveness of the programme and to improve student employability. More has been done on workintegrated learning however, little has been done on the ethical supervision and mentoring of students during WIL. The study contributes to the debate of WIL implementation. The positivist research paradigm underpinning the study led to the use of a survey research design.

\section{Positivist research paradigm}

The philosophy underpinning the study is positivism that explains that there is a single reality (Mackenzie and Knipe, 2006), which could be explained better by employing the quantitative approach. This approach resulted in the use of the survey in one programme at the Durban University of Technology (Faculty of Arts of Design) in South Africa. In order to collect data, a Likert scale questionnaire had been used. The intent of following this route of enquiry was to test the theory objectively in order to get reliable results. Thirty respondents had been selected randomly from the target population to ensure population representation. From the WIL coordinator perspective, this phenomenon could be explained better. The research ethical rules including avoiding plagiarism, fabrication and falsification of data, seeking consent, etc. have been adhered to in order to achieve reliable results.

\section{Results}

It has been discovered that WIL presents many learning opportunities when supervisors and mentors have been adequately trained to execute their roles during a WIL placement. However, the research revealed that there are no comprehensive supervisor/mentor development programmes in many universities, particularly the university under study. Thus, universities need to develop a comprehensive development programme for both academic and industry supervisors/mentors to ensure ethical supervision and mentoring of students. Consequently, there is a shortage of mentors, a lack of mentoring capacity and uncertainty in working with young mentees.

Moreover, universities do need analysis for both students and supervisors/mentors so that all stakeholders will perform well in their roles during placement. Institutions and employers do not

\footnotetext{
${ }^{1}$ Faculty of Arts and Design, Durban University of Technology, cabangile12@ hotmail.com
} 
understand that they have a reciprocal relationship regarding student placement. Employers and institutions need to understand their reciprocal relationship as they need each other to improve student employability. Departments and Programmes that do not have effective WIL should implement it for the sake of students as it has been discovered that some Programmes do not implement WIL at all. All stakeholders need to help students to bridge a wide gap between theory and practice through ethical execution of WIL to enhance students' employability. Students should not be used for errands in organisations as this impacts on their morale as it has been revealed that students end up doing irrelevant tasks. Monitoring and evaluation are crucial during placement to ensure ethical supervision and mentoring of students. Universities need to open a platform where students, employers and other stakeholders provide feedback to enhance the curriculum and student employability. University leadership at all levels need to look into ethical and effective implementation of WIL throughout the institution.

\section{Discussion}

Supervision is about execution of determined educational goals. Supervision is a responsibility of institutions and employers during WIL placements. In addition, during the WIL placement students require both academic and industrial supervisors. About $95 \%$ of respondents agreed with this because these supervisors play different vital roles on students' career. Weible (2010) concurs by asserting that academic supervisors set learning objectives by ensuring improved communication between students and employers for feedback reasons. Schilling and Klamma (2010) concur by stating that academic supervisors are responsible for the development of self-learning skills, conflict identification and resolution skills, as well as assessing and monitoring student performance at the workplace. Additionally, an institution prepares students, facilitates integration of learning, and monitors work integrated placements and experiences.

In order to ensure that students' supervision during placement is ethical, employers and industry supervisors should play their roles effectively. Tynjala (2009) supports this by elucidating that the industry supervisors orientate students into the organisation by stating the learning objectives (the students have to achieve), identifying skills students need, and arranging the required training. The industry supervisor must be someone who is available to students with relevant expertise. The student may rotate through various units in the organisation to acquire broad-based experience however, there should be one supervisor to oversee. Therefore, the industry supervisor needs to be a person with strong leadership and good communication skills and patience. It is essential that these stakeholders empower students in various ways as their roles have been stated. All stakeholders contribute tremendously towards students' employability and growth, so is WIL. It is vital to execute WIL ethically and efficiently with a high degree of commitment from all relevant stakeholders.

The organisation has to provide relevant work and on-site supervision. On the other hand, the students need to exploit learning opportunities both the organisation and the supervisor provide. Furthermore, Maphosa and Ndaba (2012) elucidates that the students should be professional in terms of timely task completion and submission as well as proper dress code. Some of the respondents (58\%) explained that there are cases where they only or mostly do duties that are not relevant to their career. Keating (2006) explains that organisations tend to be reluctant to give students proper tasks because students are inexperienced and they may mess up. This could ruin their relationship with their clients. Some respondents stated that no one visits them in the field from the institution. They explained that they have one day allocated for WIL in a week, which is Wednesday. It is either you do your WIL or spend your time on other things that seem important and pressing to you. The respondents explained that they get to be advised to look for WIL in schools as many graduates are employed at TVET colleges; yet, they are not trained to be teachers. It turned out that was an exaggeration because only less than five graduates from the Programme had been employed at TVET colleges. Employers do not want to accept them for one day in a week. Consequently, their employment rate is extremely low on the course they are qualified for. They resort to enrolling for the Post Graduate Certificate in Education (PGCE) and become Language teachers. This is highly unethical and does not reflect student centeredness. Students enroll for a course they are passionate about. Channelling them towards other career paths is unfair.

Institutions are responsible for monitoring WIL placement to ensure that all stakeholders perform their roles efficiently. Monitoring could be done through site visits, email, phone calls, and chat rooms. The 
three-legged relationship (student, university supervisor and industry supervisor) requires efficient monitoring in order to ensure ethical supervision. Tynjala (2009), Maphosa and Ndaba (2012) Weible (2010) elude to the fact that in most cases both academic and industry supervisors are poorly and not prepared for their roles; and $94 \%$ of the respondents agreed to this point. Since these students do not have proper WIL they cannot have someone to monitor their WIL. The Programme needs to implement WIL first if it cares about these students' career, and then ensure proper monitoring of WIL because the respondents revealed the ineffectiveness of the WIL.

Both the institution supervisors and industry supervisors' evaluation of students during WIL placement is critical to identify strengths and weaknesses. Moreover, Keating (2006) posits that evaluation helps avoid problems related to WIL placements such as misunderstanding of job roles, miscommunication, lack of objectives and goals. Supervisors evaluate the achievement of learning goals, skill and job knowledge, development, dependability, punctuality, attendance, human relations, attitude and capability. The empirical data correlates with theoretical data as $100 \%$ of respondents agreed that both supervisors evaluate the achievement of the above mentioned skills.

Both employers and students have a responsibility of giving feedback to the institution whether the programmes and practices are relevant and current or not, in order to enhance the curriculum. This requires effective communication throughout WIL placement. Ideally this is a standard practice; however, the Programme under study will not enjoy this benefit due to the lack of effective WIL. This will result in chopping and changing the curriculum because there is no one monitoring and evaluating the WIL which will lead to the feedback.

Mentoring places greater emphasis on personal development and growth of students. Mentoring involves assisting and supporting students to navigate through their career and find their niche. During this process, they need a space to grow and come up with new ideas and new ways of executing tasks. To achieve this, they must be thrown into the deep while surrounded by mentors to provide safety nets when they drown. Chiappetta-Swanson and Watt (2011) contend that mentoring is the transmission of knowledge and any other form of support given to recipients related to professional development. It encompasses informal communication between a mentor and a mentee (protégé). Maphosa and Ndaba (2012) further explain that a mentor and a mentee engage in an on-going relationship based on mutual agreement. More than $80 \%$ of respondents agreed that mentoring leads to personal and professional development hence, specified curriculum requirements should inform it. The Socio-cultural theory concurs as it believes in student development in every aspect. The respondents also mentioned that mentoring is far better than supervision as it provides a semi-formal mode of learning. Supervision and mentoring characteristics should be merged and implemented for the effectiveness of WIL.

A mentor could be either from the academic institution or industry. Duckett (2004) maintains that mentoring helps students to gain independence, confidence and time management competencies. In addition, a mentor helps students plan their career goals and networking in the field of interest and exchange of ideas. This broadens the horizons of students. However, there are some challenges centering on mentoring including the shortage of mentors, a lack of mentoring capacity and uncertainty in working with different mentees and younger generations. The respondents (79\%) agreed with the literature that both supervisors do not get proper training. As a result they lack skills of supervision, mentoring, assessing and resolving conflicts which arise during the process of supervision and mentoring. Both the theory and respondents concur with the literature that WIL, supervision and mentoring have a broadening effect on students. Finally, the literature and respondents (73\%) agree that both supervision and mentoring enhance students' learning experience during WIL placement. Students gain various skills and competencies that prepare them for employment. If supervision and mentoring during placement could be ethical and effective students' employment chances will be high. Programmes that implement WIL effectively and efficiently in the same institution have a high degree of student employment as opposed to this one under study. Some students from those Programmes get jobs during WIL placement. The theory has been used in the subsequent section for better explanation.

\section{Socio-cultural theory}

Socio-cultural theory is highly concerned about student development. Hutchins (1993) purports that the use of socio-cultural theory for professional education could be substantiated by work place learning. In addition, Spouse (2000) agrees by saying that this theory helps to bridge theory and 
practice in the supervisory relationship. Therefore, in order for learning to succeed it is necessary to enforce effective social interactions between a supervisor/mentor and a student through language development and by empowering students to merge theoretical material with practical experience. Chisholm et al. (2009) further contend that WIL is based on the theory of experiential learning. Thus, true education occurs when students solve problematic situation in real life and authentic environments.

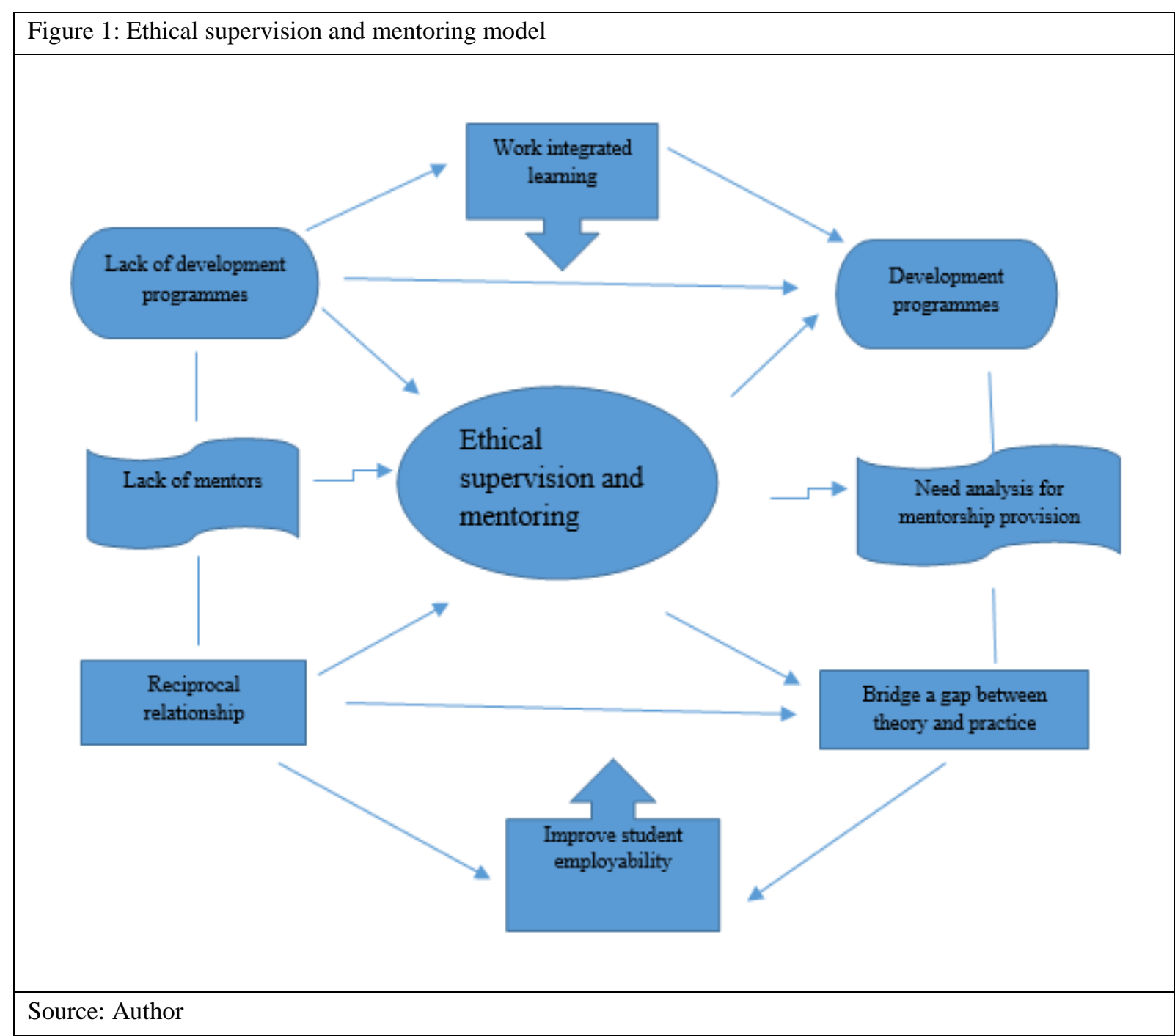

\section{Conclusion}

The work integrated learning improves employability of graduates and it entails supervision and mentoring. However, the survey revealed that the programme lacks efficiency due to the lack of proper training of the supervisors and mentors. Involved stakeholders need to improve their practice to ensure ethical supervision and mentoring

\section{References}

Chiappetta-Swanson, C. \& Watt, S. (2011). Good Practice in the Supervision and Mentoring of

Postgraduate Students: It Takes an Academy to Raise a Scholar. Hamilton: Ontario, McMaster University.

Chisholm, C., Harris, M., Northwood, D. \& Johrendt, J. (2009). The Characteristics of Work-Based

Learning by Consideration of the Theories of Experiential Learning. European Journal of Education, 44 (3), 1-9.

Duckett, S. (2004). Funding Model Rewards Only the Few. Melbourne: Oxford University Press.

Hutchins, E. (1993). Learning to Navigate. Cambridge: Cambridge University Press.

Keating, S. (2006). Learning in the Workplace: A Literature Review. Victoria University. Post

Compulsory Education Centre, 1-40. Retrieved August 20, 2013 from

http://tls.vu.edu.au/PEC/PECdocsPCEC\%20LIW\%20literarure\%20review\%20final.pdf 
Mackenzie, N. \& Knipe, S. (2006). Research Dilemmas: Paradigms, Methods and Methodology.

Issues in Educational Research, 16 (4), 1-5.

Maphosa, R. \& Ndaba, G.T. (2012). Supervision and Assessment of Student Teachers: A Journey

of Discovery for Mentors in Bulawayo. Zimbabwe. Journal of Emerging Trends in Educational Research and Policy Studies, 3 (1), 1-7.

Schilling, J. \& Klamma, R. (2010). The Difficult Bridge between University and Industry: A Case

Study in Computer Science Teaching. Assessment and Evaluation in Higher Education, 35 (3), 253-261.

Spouse, J. (2000). Talking Pictures: Investigating Personal Knowledge through Illuminative

Artwork. Nursing Times Research, 5 (2), 253-261.

Tynjala, P. (2009). "Connectivity and Transformation in Work-Related Learning-Theoretical

Foundations", Springer, 11-37.

Weible, R. (2010). Are Universities Reaping the Available Benefits Internship Programmes Offer?

Journal of Education for Business, 85 (3), 59-63. 